\title{
Kepuasan Kerja, Komitmen Organisasi dan Turnover Intention: Studi Pada Pegawai Honorer di Kabupaten Grobogan
}

\author{
Nurma Adi Setyaningrum ${ }^{1}$, Edi Cahyono ${ }^{2}$

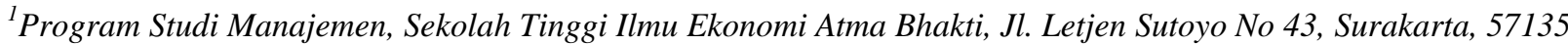 \\ Email: nurmaadi28@gmail.com \\ ${ }^{2}$ Program Studi Manajemen, Sekolah Tinggi Ilmu Ekonomi Atma Bhakti, Jl. Letjen Sutoyo No 43, Surakarta, 57135 \\ Email: edicahyono73@yahoo.co.id
}

\begin{abstract}
The purpose of this study is to examine the effect of job satisfaction and organizational commitment on turnover intention. Data were collected from 60 honorary employees at regency Grobogan by using a convenience sampling. The statistical method is multiple regression analysis. The result of this research which is showed that job satisfaction and organizational commitment have a positive and significant effect on turnover intention.
\end{abstract}

Keywords - : Job Satisfaction; Organizational Commitment; Turnover Intention.

\section{PENDAHULUAN}

Fenomena turnover intention pada pegawai honorer merupakan topik penelitian yang relatif masih penting untuk dikaji. Hal ini dikarenakan pegawai honorer merupakan pekerja yang terikat oleh sebuah kontrak kerja dan belum diangkat menjadi pegawai tetap di dalam suatu organisasi atau perusahaan. Ketidakpastian dalam hal pekerjaan dimasa depan membuat para pegawai honorer menjadi tidak loyal pada organisasi, atau dalam bahasa yang lain memiliki tingkat turnover intention tinggi.

Pada beberapa perusahaan, pegawai yang berstatus honorer mendapatkan tuntutan yang tinggi untuk terus bekerja dan bertaut didepan komputer berjam-jam bahkan sampai lembur (Sidanti, 2015). Hal ini menyebabkan para pegawai honorer mengalami stress kerja dan berdampak pada individu ingin pindah kerja. Stress kerja merupakan faktor penyebab tingginya tingkat turnover intention (Liu et al., 2019; Miligi et al., 2019).

Berdasarkan hasil review terhadap penelitian terdahulu, ada beberapa faktor penting yang mempengaruhi turnover intention. Faktor penting tersebut diantaranya: kepuasan kerja karyawan (lihat Cahyono, 2013; Chan \& Ao, 2019; Ekhsan, 2019; Cahyono et al., 2020a), komitmen organisasi (lihat Kurniawan \& Cahyono, 2014; Chan \& Ao, 2019; Ekhsan, 2019), supervisi abusive (lihat Haryanto \& Cahyono, 2019; Cahyono et al., 2020a; Cahyono et al., 2020b), lingkungan kerja (lihat Jung \& Park, 2019; Kurniawaty et al., 2019; Li et al., 2019). Penelitian ini fokus pada kepuasan kerja dan komitmen organisasi sebagai variabel yang dikonsepkan dapat mempengaruhi tingkat turnover intention. Hal ini didasarkan pada hasil studi pendahuluan yang dilakukan dengan melakukan wawancara singkat dengan beberapa pegawai honorer.

Dalam penelitian ini ada 3 variabel amatan, yaitu: kepuasan kerja, komitmen organisasi, dan turnover intention. Kepuasan kerja dan komitmen organisasi dikonsepkan sebagai variabel independen yang dapat mempengaruhi tingkat turnover intention pegawai. Individu yang memiliki tingkat kepuasan kerja yang tinggi cenderung memiliki tingkat turnover intention yang rendah. Begitu pula individu yang memiliki komitmen organisasi yang tinggi cenderung memiliki tingkat turnover intention yang rendah, begitu juga sebaliknya.

\section{LANDASAN TEORI DAN PENGEMBANGAN HIPOTESIS}

\section{A. Kepuasan kerja dan Turnover intention}

Kepuasan kerja merupakan faktor penting karena hal ini menyumbang keberhasilan perusahaan maupun organisasi, antara lain dapat meningkatkan produktifitas kerja. Yulianto (2001) menyatakan bahwa kepuasan kerja memiliki hubungan erat terhadap pikiran untuk berhenti kerja dan niat untuk mencari pekerjaan lain (turnover intention). Semakin rendah kepuasan kerja pegawai, semakin tinggi turnover intention.

Ada beberapa penelitian yang menunjukan bahwa kepuasan kerja berhubungan dengan turnover intention (Chan \& Ao, 2019; Ekhsan, 2019). Abdurrahim et al., (2017) meneliti tentang kepuasan kerja dan turnover intention dan hasilnya kepuasan kerja berpengaruh signifikan terhadap turnover intention. Khan et al., (2014) melakukan penelitian tentang kepuasan kerja dan turnover intention, dan menemukan hasil kepuasan kerja berpengaruh negatif dan signifikan terhadap turnover intention. Berdasarkan hasil studi terdahulu yang telah diuraikan, maka hipotesis pertama dalam penelitian ini adalah :

H1 : Kepuasan kerja berpengaruh negatif dan signifikan terhadap turnover intention . 
Website : http://ekomaks.unmermadiun.ac.id/index.php/ekomaks

\section{B. Komitmen Organisasi dan Turnover Intention}

Komitmen organisasi merupakan variabel yang sangat penting untuk memahami sikap seorang pegawai terhadap suatu organisasi. Pegawai yang memiliki kecenderungan turnover biasanya memiliki loyalitas yang rendah terhadap organisasinya. Kondisi tersebut terjadi karena individu yang memiliki kecenderungan mengundurkan diri biasanya sudah tidak menyukai tempat kerjanya, tidak memiliki niat untuk merealisasikan tujuan organisasinya. Yulianto (2001) menyatakan bahwa komitmen organisasi berpengaruh negatif dan signifikan terhadap turnover intention.

Ada beberapa penelitian tentang hubungan komitmen organisasi dengan turnover intention (Chan \& Ao, 2019; Ekhsan, 2019). Ekhsan (2019) dalam penelitiannya menemukan hasil bahwa komitmen organisasi berpengaruh negatif dan signifikan terhadap turnover intention. Penelitian yang dilakukan oleh Cohen (1993) menemukan bahwa komitmen organisasi berpengaruh negatif dan signifikan terhadap turnover intention. Hal ini berarti semakin rendah komitmen organisasi,maka semakin tinggi turnover intention. Berdasarkan hasil penelitian terdahulu yang telah diuraikan, maka hipotesis kedua dalam penelitian ini adalah :

H2 : Komitmen organisasi berpengaruh negatif dan signifikan terhadap turnover intention.

\section{III.METODE PENELITIAN}

\section{A. Populasi, Sampel dan Teknik Sampling}

Populasi dalam penelitian ini adalah seluruh pegawai honorer yang bekerja di Kabupaten Grobogan. Dalam penelitian ini kuesioner yang disebar sebanyak 68. Kuesioner disebarkan dalam jangka waktu dua minggu dimana penyebaran kuesioner dilakukan langsung oleh peneliti kepada responden. Jumlah kuesioner yang dapat dikumpulkan kembali oleh peneliti sejumlah 60 kuesioner (responden rate 88\%). Seluruh kuesioner yang kembali layak untuk diuji. Teknik sampling yang digunakan dalam penelitian ini adalah non-random sampling dengan menggunakan metode convenience sampling.

\section{B. Definisi Operasional dan Pengukuran Variabel}

Kepuasan Kerja. Kepuasan kerja adalah seperangkat perasaan individu yang tentang menyenangkan atau tidak pekerjaan yang mereka kerjakan. Kepuasan kerja diukur dengan menggunakan 5 item pertanyaan kuesioner yang diadopsi dari Alshitri (2013) dan Cahyono (2013).

Komitmen Organisasi. Komitmen organisasi adalah suatu keadaan dimana seorang pegawai memihak pada organisasinya dan berkeinginan mempertahankan keanggotaan dalam organisasinya. Komitmen organisasi diukur dengan menggunakan 5 item pertanyaan kuesioner yang diambil dari Allen \& Mayer (1990) dan Kurniawan \& Cahyono (2014).

Turnover Intention. Turnover intention adalah kesediaan individu untuk meninggalkan organisasi tempat ia bekerja atau berpindah keorganisasi lain. Turnover intention diukur menggunakan 5 item pertanyaan kuesioner yang diambil dari Mobley et al., (1978) dan Cahyono et al., (2020a).

\section{Metode Analisis Data}

Uji Validitas dan Reliabilitas Instrumen. Pengujian validitas instrumen yang digunakan adalah Korelasi Product Moment, dimana setiap item pertanyaan harus mempunyai nilai pearson correlation yang $\geq 0,50$ dan tingkat signifikansi dibawah 0,05 (Ghozali, 2001). Uji reliabilitas bertujuan untuk mengetahui tingkat konsistensi terhadap instrumen-instrumen yang mengukur konsep. Uji Reliabilitas dalam penelitian ini menggunakan metode Cronbach Alpha. Uji validitas dan reliabilitas dalam penelitian ini menggunakan bantuan software SPSS versi 20.

Uji Hipotesis. Untuk menguji pengaruh variabel independen terhadap variabel dependen, digunakan analisis Regresi Linier Sederhana menggunakan bantuan alat software SPSS versi 20.

\section{IV.HASIL DAN PEMBAHASAN}

\section{A. Analisis Deskriptif Karakteristik Responden}

Tabel 1 menunjukkan deskripsi karakteristik responden berdasarkan jenis kelamin, usia, tingkat pendidikan, masa kerja, dan status pernikahan. Berdasarkan jenis kelamin dikelompokkan menjadi dua, yaitu laki-laki dan perempuan. Responden laki-laki sebanyak 33 orang atau 55\% dan responden perempuan sejumlah 27 orang atau 45\%, sehingga dapat disimpulkan bahwa jumlah responden laki-laki lebih banyak dari pada perempuan.

Berdasarkan usia, responden yang berusia dibawah 30 tahun sebanyak 24 orang atau $40 \%$, usia $31-40$ tahun sebanyak 27 orang atau $45 \%$, dan usia $41-50$ tahun sebanyak 9 karyawan atau 15\%. Sehingga dapat disimpulkan bahwa responden terbanyak berdasarkan usia merupakan responden yang berada dalam usia yang berkisar antara $31-40$ tahun, dan disusul responden dengan usia dibawah 30 tahun.

Berdasarkan tingkat pendidikan, responden yang mempunyai tingkat pendidikan SMA/SMK sebanyak 23 orang atau 38.3\%, responden yang mempunyai tingkat pendidikan D3 sebanyak 8 orang atau 13.3\%, dan responden yang mempunyai tingkat pendidikan S1 sebanyak 29 orang atau 48.4\%. Tingkat pendidikan S1 yang mendominasi tingkat pendidikan responden. 
Deskripsi berdasakan masa kerja menunjukkan bahwa jumlah responden masa kerja $1-5$ tahun sebanyak 25 orang atau $41.7 \%$, kemudian respoden dengan masa kerja 6 - 10 tahun sebanyak 8 orang atau $13.3 \%$, dan responden dengan masa kerja 11 -20 tahun sebanyak 27 orang atau $45 \%$.

Deskripsi berdasarkan status pernikahan menunjukkan bahwa responden yang belum menikah sebanyak 22 orang atau $36.7 \%$, dan yang sudah menikah sebanyak 38 orang atau 63.3\%. Artinya, responden yang sudah menikah lebih mendominasi.

\begin{tabular}{lcc}
\multicolumn{3}{c}{ Tabel 1. Deskripsi Responden } \\
\hline Variabel & Jumlah Responden & Persentase (\%) \\
\hline Jenis Kelamin & 33 & 55 \\
$\quad$ Laki - laki & 27 & 45 \\
$\quad$ Perempuan & & \\
Usia & 24 & 40 \\
$\quad$ < 30 tahun & 27 & 45 \\
$31-40$ tahun & 9 & 15 \\
$41-50$ tahun & & \\
Tingkat Pendidikan & 23 & 38.3 \\
SMA/SMK & 8 & 13.3 \\
D3 & 29 & 48.4 \\
S1 & & \\
Masa Kerja & 25 & 41.7 \\
1 - 5 tahun & 8 & 13.3 \\
6 - 10 tahun & 27 & 45 \\
11 - 20 tahun & & \\
Status Pernikahan & 22 & 36.7 \\
$\quad$ Belum Menikah & 38 & \\
$\quad$ Menikah & $\mathbf{6 0}$ & \\
N & & \\
\hline
\end{tabular}

Sumber: data primer yang diolah, 2020

\section{B. Hasil Uji validitas}

Uji validitas dalam penelitian ini menggunakan Confirmatory factor analysis (CFA). Berikut hasil rincian hasil uji validitas instrumen:

\begin{tabular}{|c|c|c|c|}
\hline Variabel & Item & $\begin{array}{l}\text { Nilai } \\
\text { factor } \\
\text { loading }\end{array}$ & Keterangan \\
\hline Kepuasan & Merasa senang melaksanakan tugas dalam pekerjaan & .615 & Valid \\
\hline \multirow[t]{4}{*}{ Kerja } & Merasa gaji yang diterima sesuai dengan pekerjaan & .823 & Valid \\
\hline & Merasa nyaman dengan rekan kerja & .836 & Valid \\
\hline & Merasa senang dengan atasan yang memperhatikan bawahannya & .635 & Valid \\
\hline & Merasa lingkungan tempat bekerja baik dan fasilitas memadai & .742 & Valid \\
\hline Komitmen & Hal terpenting dalam hidup adalah keterlibatan dalam bekerja & .765 & Valid \\
\hline \multirow[t]{4}{*}{ Organisasi } & Merasa hidup dalam pekerjaan & .828 & Valid \\
\hline & Merasa persoalan tempat bekerja merupakan persoalan sendiri & .530 & Valid \\
\hline & $\begin{array}{l}\text { Merasa nyaman dengan organisasi sebagai tempat } \\
\text { melangsungkan hidup dan bekerja }\end{array}$ & .651 & Valid \\
\hline & Bersedia untuk menghabiskan sisa karir pada tempat kerja & .628 & Valid \\
\hline Turnover & Sering berfikir untuk meninggalkan pekerjaan & .403 & Tidak Valid \\
\hline \multirow[t]{4}{*}{ Intention } & Sering mencari informasi mengenai pekerjaan lain & .805 & Valid \\
\hline & Sering berfikir untuk memulai atau membuka bisnis sendiri & .834 & Valid \\
\hline & Berfikir untuk mencari pekerjaan lain & .788 & Valid \\
\hline & Sering gelisah saat pulang kerumah setelah bekerja & .569 & Valid \\
\hline
\end{tabular}

Tabel 2 hasil uji validitas menunjukan bahwa ada 1 item yang tidak valid pada indikator turnover intention karena nilai factor loading <0,5 sehingga item tersebut harus dikeluarkan dalam tahapan uji selanjutnya. Sedangkan item yang lain dinyatakan valid dan dapat digunakan untuk pengujian selanjutnya.

\section{Hasil Uji reliabilitas}

Tabel 3 menjelaskan hasil uji reliabilitas terhadap 3 variabel penelitian. Hasil tersebut menunjukkan bahwa ketiga variabel memiliki nilai cronbach alpha $>0,60$. Hal ini berarti bahwa variabel kepuasan kerja, komitmen organisasi, dan turnover intention dapat dikatakan reliabel, sehingga dapat digunakan untuk pengujian selanjutnya. 
Website : http://ekomaks.unmermadiun.ac.id/index.php/ekomaks

\begin{tabular}{lcc}
\multicolumn{3}{c}{ Tabel 3. Hasil Reliabilitas } \\
\hline \multicolumn{1}{c}{ Variabel } & Cronbach's Alpha & Keterangan \\
\hline Kepuasan kerja & 0,818 & Reliabel \\
Komitmen Organisasi & 0,693 & Reliabel \\
Turnover Intention & 0,624 & Reliabel \\
\hline Sumber: Data primer yang diolah, 2020 & &
\end{tabular}

Sumber: Data primer yang diolah, 2020

\section{Hasil Uji Hipotesis}

Hasil uji regresi antara kepuasan kerja dan komitmen organisasi pada turnover intention disajikan dalam tabel 4 berikut : Tabel 4. Hasil Pengujian Hipotesis Penelitian

\begin{tabular}{lcc}
\hline \multicolumn{1}{c}{ Variabel } & Koefisien & t-statistik \\
\hline Kepuasan Kerja & .239 & $2.662^{*}$ \\
Komitmen Organisasi & .496 & $4.112^{*}$ \\
& & \\
$\mathrm{~F}$ test & $22.478^{*}$ & \\
$\mathrm{R}^{2}$ & .421 & \\
\hline Keterangan: * Signifikan pada level $<05$ & &
\end{tabular}

Keterangan: * Signifikan pada level $<.05$

Sumber: Data primer yang diolah, 2020

Hasil pengujian regresi variabel kepuasan kerja pada turnover intention menunjukan bahwa nilai koefisien sebesar 0,239 dan nilai t sebesar 2,662 dengan tingkat signifikansi $<0,05$. Oleh karena itu, Hipotesis 1 yang berbunyi kepuasan kerja berpengaruh negatif dan signifikan terhadap turnover intention dinyatakan tidak didukung. Meskipun hasil pengujian ditemukan berpengaruh signifikan pada level $<0,05$, namun nilai koefisien hasil pengujian hipotesis memiliki tanda positif, sedangkan hipotesis yang diusulkan bertanda negatif, sehingga hipotesis 1 yang diusulkan dalam penelitian ini dinyatakan tidak didukung. Hasil penelitian ini mendukung penelitian terdahulu yang menyatakan bahwa kepuasan kerja berpengaruh positif dan signifikan pada turnover intention (Chan \& Ao, 2019; Ekhsan, 2019).

Selanjutnya, hasil uji regresi variabel komitmen organisasi pada turnover intention menunjukan bahwa nilai koefisien sebesar .496 dan nilai t sebesar 4.112 dengan tingkat signifikansi < 0,05. Berdasarkan hasil tersebut, Hipotesis kedua yang menyatakan bahwa komitmen organisasi berpengaruh negatif dan signifikan terhadap turnover intention dinyatakan tidak didukung. Meskipun hasil pengujian ditemukan berpengaruh signifikan pada level $<0,05$, namun nilai koefisien hasil pengujian hipotesis memiliki tanda positif, sedangkan hipotesis yang diusulkan bertanda negatif, sehingga hipotesis 2 yang diusulkan dalam penelitian ini dinyatakan tidak didukung. Hasil penelitian ini bersesuaian dengan penelitian terdahulu yang menyatakan bahwa komitmen organisasi berpengaruh positif pada turnover intention (Muhtarim. 2017; Chan \& Ao, 2019; Ekhsan, 2019).

\section{E. Pembahasan}

Berdasarkan pengujian hipotesis yang telah dilakukan dalam penelitian ini, diperoleh beberapa temuan yang menarik. Temuan yang diperoleh dari hipotesis pertama berbeda dengan beberapa studi sebelumnya, karena semakin tinggi tingkat kepuasan kerja individu, semakin tinggi pula tingkat turnover intention. Beberapa kajian sebelumnya menunjukan hasil yang kebalikan antara tingkat kepuasan kerja dengan turnover intention. Ketika karyawan merasakan kepuasan kerja yang tinggi maka tingkat turnover intention rendah.

Luthans (2006) mengungkapkan bahwa saat segala hal dalam ekonomi berjalan dengan baik dan sedikit pengangguran, pergantian karyawan akan tetap meningkat karena orang akan mulai mencari kesempatan yang lebih baik, sekalipun puas banyak orang yang ingin keluar jika ada kesempatan yang lebih menjanjikan. Robbins (2008) menyatakan bahwa semakin tua seorang individu, semakin kecil kemungkinan karyawan untuk keluar dari pekerjaannya. Karyawan dengan usia muda, terutama dalam masa yang masih tergolong produktif memiliki keinginan yang lebih kuat untuk keluar dari pekerjaannya, karena mereka memiliki pemikiran untuk terus mencari sesuatu yang baru dan lebih baik kedepan. Karyawan dengan usia muda sangat sensitive dengan pekerjaan lain yang lebih baik dan lebih menjanjikan kedepan. Sehingga dapat disimpulkan bahwa pegawai honorer mempunyai keinginan berpindah dengan harapan dapat menikmati peningkatan karir dan pekerjaan yang lebih baik.

Selanjutnya, berdasarkan hasil pengujian hipotesis kedua juga diperoleh temuan yang menarik. Beberapa penelitian terdahulu menunjukan bahwa komitmen organisasi yang tinggi maka niat berpindah kerja rendah. Namun pada penelitian ini, semakin tinggi komitmen organisasi tingkat turnover intention juga tinggi. Hasil penelitian ini berbeda dengan beberapa penelitian terdahulu dalam konteks hubungan antara komitmen organisasi dan turnover intention. Hal ini kemungkinan disebabkan oleh perbedaan karakteristik pada profil responden. Dalam penelitian ini, sebagian besar responden berpendidikan SMA/SMK dan juga merupakan lulusan baru. Minimnya pengalaman dan kemampuan yang dimiliki responden akan membuat mereka tetap bangga dan berkomitmen untuk bekerja diperusahaan, akan tetapi mereka dapat pergi kapan saja dari organisasi ketika ada kesempatan yang lebih baik mereka berfikir untuk keluar. Hal ini menunjukkan bahwa karyawan yang kurang memiliki loyalitas yang baik. Saat karyawna merasa sudah mempelajari semua aspek dari suatu organisasi, maka mereka merasa lebih nyaman untuk berpindah atau banyak pula yang membuka usaha sendiri. 
Website : http://ekomaks.unmermadiun.ac.id/index.php/ekomaks

\section{KESIMPULAN}

\section{A. Kesimpulan}

Berdasarkan hasil dan pembahasan yang telah dijelaskan, maka simpulan penelitian ini adalah kepuasan kerja berpengaruh positif dan signifikan terhadap turnover intention Pegawai honorer di kabupaten Grobogan. Komitmen organisasi juga ditemukan berpengaruh positif dan signifikan terhadap turnover intention pegawai honorer di kabupaten Grobogan. Kedua hipotesis yang diusulkan dalam penleitian ini dinyatakan tidak didukung.

\section{B. Keterbatasan dan saran}

Dalam penelitian ini terdapat beberapa keterbatasan yang ditemukan. Pertama, variabel independen yang digunakan dalam penelitian ini hanya mencakup 2 variabel saja yaitu kepuasan kerja dan komitmen organisasi, sehingga untuk penelitian selanjutnya masih perlu kajian tentang variabel- variabel independen diluar model penelitian ini seperti: lingkungan kerja,keamanan kerja,stress kerja. Kedua, dalam penelitian ini pengambilan data hanya menggunakan kuesioner, sehingga sangat mungkin data diperoleh dari jawaban responden terbatas sehingga kedalaman data masih kurang untuk menggali variabel yang diteliti. Penelitian selanjutnya diharapkan menambah metode pengambilan data seperti wawancara maupun melakukan observasi secara langsung.

Untuk kepentingan praktis, sebaiknya organisasi lebih memperhatikan kesejahteraan pegawainya, dengan meningkatkan kepuasan kerja, sehingga persepsi pegawai yang berkeinginan berpindah dapat dihindarkan. Selanjutnya, instansi atau organisasi diharapkan untuk lebih menanamkan loyalitas pada diri pegawainya. Hal ini dikarenakan loyalitas terhadap organisasi itu merupakan hal yang penting, terutama pegawai dengan usia muda dan merupakan lulusan baru, karena cenderung memiliki tingkat turnover tinggi.

\section{VI.DAFTAR PUSTAKA}

Abdurrahim, Hastin Umi Anisah \& Maya Sari (2017). Pengaruh Kepuasan Kerja dan Komitmen Organisasi Terhadap Turnover Intentionn (Studi Pada Bank Perkreditan Rakyat Mitratama Arthabuana). Jurnal Ilmiah Manajemen, 1 (2): 1-11.

Allen N.J \& Mayer J. (1990). The Measurement And Antecedent Of Affective, Continuance And Normative Commitment To The Organization. Journal Uccup Psycol, 63, 1- 18

Alshitri, K. I. (2013). An Investigation of Factors Affecting Job Satisfaction among R\& D Center Employees in Saudi Arabia. Journal of Human Resources Management Research, vol 2013, Article ID 279369, DOI: 10.5171/2013.279369.1-10.

Cahyono, E. 2013. Pengaruh Kepuasan Kerja pada Organizational Citizenship Behaviour (OCB) dengan Komitmen Tim sebagai Variabel Pemoderasi. Riset Manajemen dan Akuntansi STIE Atma Bhakti, 4 (7).

Cahyono, E., Haryono, T., Haryanto, B., Harsono, M. 2020. A New Insight in Relation between Abusive Supervision and Work Outcomes: A Conceptua Review. Quality-Access to Success, 21 (177), 26-30. (a)

Cahyono, E., Haryono, T., Haryanto, B., Harsono, M. 2020. The Role of Gender in the Relationship Between Abusive Supervision and Employee's Organizational Citizenship Behaviour in Indonesia. International Journal of Trade and Global Markets, 13 (3), 311-322. (b)

Chan, S. H. J., \& Ao, C. T. D. (2019). The mediating effects of job satisfaction and organizational commitment on turnover intention, in the relationships between pay satisfaction and work-family conflict of casino employees. Journal of Quality Assurance in Hospitality \& Tourism, 20(2), 206-229.

Cohen, Aaron (1993). Organizational Commitmen and Turnover : A MetaAnalysis. The Academy of Management Journal. Vol.36, Num. 5. Pp. 1140- 1157

Ekhsan, M. (2019). The influence job satisfaction and organizational commitment on employee turnover intention. Journal of Business, Management, and Accounting, 1(1), 48-55.

Ghozali, I. (2013). Aplikasi Analisis Multivariate Dengan Program IBM SPSS 21. Semarang: Badan Penerbit Universitas Diponegoro.

Haryanto, B., \& Cahyono, E. 2019. Relationship Between Abusive Supervision and Performance: The Role of Gender. European Research Studies Journal, 22 (3), 305-311

Jung, J. Y., \& Park, M. J. (2019). The effects of emotional labor, Resilience, and nursing work environment on turnover intentions of comprehensive nursing care medical service nurses. Journal of Digital Convergence, 17(3), 281-290.

Kurniawan, F., \& Cahyono, E. 2014. Hubungan Konflik Peran pada Komitmen Organisasi: Kepuasan dan Stres Kerja sebagai Variabel Mediasi. Riset Manajemen dan Akuntansi STIE Atma Bhakti, 5 (10).

Khan, Alamdar Hussain, dan Aleem, Muhammad (2014). Impact of Job Satisfaction on Employee Turnover: An empirical study of Auotonomous Medical Institutions of Pakistan. Journal of International Studies, Vol.7, Num.1.pp.122-132

Kurniawaty, K., Ramly, M., \& Ramlawati, R. (2019). The effect of work environment, stress, and job satisfaction on employee turnover intention. Management Science Letters, 9(6), 877-886.

Li, B., Li, Z., \& Wan, Q. (2019). Effects of work practice environment, work engagement and work pressure on turnover intention among community health nurses: Mediated moderation model. Journal of Advanced Nursing, 75(12), 3485-3494.

Liu, J., Zhu, B., Wu, J., \& Mao, Y. (2019). Job satisfaction, work stress, and turnover intentions among rural health workers: a cross-sectional study in 11 western provinces of China. BMC family practice, 20(1), 9

Luthans, F. (2006). Perilaku Organisasi. Edisi 10. Yogyakarta: Penerbit Andi.

Miligi, E., Alshutwi, S., \& Alqahtani, M. (2019). The Impact of Work Stress on Turnover Intentions among Palliative Care Nurses in Saudi Arabia. International Journal of Nursing, 6(2), 84-88.

Muhtarim, H. S. (2017). Pengaruh Kepuasan Kerja dan Komitmen Organisasi Terhadap Turnover Intention Karyawan PT XYZ. Jurnal Teknik Industri, Vol 5 no 3.

Mobley, Horner \& Hollingsworth. (1978). The relationship between human resource practice and employee retention in public organisation: an explanatory study conducted in the united arab emirates. International Journal of Business and Social Science.

Robbins, S. (2008). Organizational Behaviour, Tenth Edition, New Jersey. Prentice/ Hall International, Inc.

Sidanti, H. (2015). Pengaruh Lingkungan Kerja, Disiplin Kerja dan Motivasi Kerja Terhadap Kinerja Pegawai Negeri Sipil Di Sekertariat DPRD Kabupaten Madiun. Jurnal JIBEKA , 9 (1) : 44- 53.

Yulianto, W. (2001). Pengaruh Kepuasan Kerja, Loyalitas Karyawan, Komitmen Organisasi dan LMX pada TurnoverIntention Di Lingkungan Asuransi Skripsi Program Sarjana Jurusan Manajemen. 